\title{
CLINICAL EVALUATION OF POLYOXYMETHYLENE PARTIAL DENTURES DESIGNED AND FABRICATED BY USING CAD/CAM TECHNOLOGY
}

\author{
Haitham A. Ismail $B D S^{1}$, Faten S. Abbas $P h D^{2}$, Nazik A. El Gindy $P h D^{3}$
}

\begin{abstract}
INTRODUCTION: Recent researches had shown that, in principle, computer-assisted design, computer-assisted manufacture and rapid prototype technologies (CAD/CAM) can be successfully applied to the fabrication of removable partial denture (RPD) alloy frameworks and replace laboratory crafting techniques. The (CAD/CAM) techniques have been widely used for a long time to manufacture dental prostheses. Polyoxymethylene (POM) also known as acetal resin has been used as an alternative tooth- colored denture base and denture clasps material since 1986 and was promoted primarily for superior esthetic.

OBJECTIVES: To evaluate clinically the use of Polyoxymethylene partial dentures designed and fabricated by using CAD/CAM technology compared to conventional cobalt chromium partial denture through both the masticatory efficiency and patient satisfaction.

MATERIALS AND METHODS: This clinical trial was conducted on twenty mandibular partially edentulous patients (Kennedy class I) who received two types of RPD. Type I was Polyoxymethylene partial denture designed and fabricated by using CAD/CAM Technology and Type II was cobalt chromium partial denture fabricated using the conventional technique.At time of denture insertion, the masticatory efficiency of both types of dentures was evaluated for each patient .After 3 months of denture use, each patient was clinically evaluated through both the masticatory efficiency and patient satisfaction.

RESULTS: Type I RPD showed better masticatory efficiency than Type II RPD but without statistical significant values at different follow up periods. Patients showed more satisfaction with type I RPD than with type II RPD with a significant value.

CONCLUSIONS: Polyoxymethylene partial denture designed and fabricated by using CAD/CAM Technology is a favorable treatment for partially edentulous patients showing improvement of masticatory efficiency and favorable patient satisfaction.

KEYWORDS: CAD CAM, Polyoxymethylene, cobalt chromium, Partial Denture.
\end{abstract}

1. B.D.S. Prosthodontic Department, Faculty of dentistry, Alexandria University, Alexandria, Egypt

2. Professor of Prosthodontic, Faculty of dentistry, Alexandria University, Alexandria Egypt

3. Professor at Industrial Pharmacy Department, Faculty of Pharmacy, Alexandria University, Alexandria Egypt

Corresponding author:

E-mail: haithamrossonero@yahoo.com

\section{INTRODUCTION}

A Removable partial denture (RPD) is an excellent treatment modality to restore partial loss of teeth and supporting structures in order to restore function, esthetics, phonetics and tissue preservation.

Fabricating an esthetically pleasing RPD while avoiding the unsightly display associated with conventional clasp assemblies often presents a challenge to the dentist (1). The traditional use of the metal clasp like cobalt chromium (Co$\mathrm{Cr}$ ), gold, stainless steel, and titanium hampers esthetics, since its obvious display conflicts with patient's prosthetic confidentiality. Methods to overcome this esthetic dilemma include the painting of clasps with tooth colored resin (2), use of lingually positioned clasps $(3,4)$, engagement of mesial rather than distal undercuts (5), and use of gingival approaching clasps (3). Unless clasps can be avoided by using precision attachments, some of the RPD framework will be invariably visible (6).

Synthetics, as well as metal alloys, are used, among other materials, in dentistry for denture fabrication. The most common denture materials are derived from methyl polymethacryl, which is classified as an acrylic substance (7). Polyoxymethylene (POM) also known as acetal resin has been used as an alternative tooth-colored denture base and denture clasps material since 1986 and was promoted primarily for superior esthetic. Acetal resins (acetyl resin) are formed by the polymerization of formaldehyde. Because of its compatibility, it was considered as RPD framework for patients with allergic reaction to co-chromium alloy (8).
Fitton et al. (9), tested some physical characteristics of POM (acetal resin) for dental use like the modulus of elasticity in compression, extension, and flexure, stress relaxation, force displacement behavior of clasp forms, impact strength, and glass transition temperature. Results showed that resin clasp may be resilient enough to engage the undercuts for the retention of RPD. But the low flexural modulus requires the resin to be used in a greater crosssectional area than the metal alloys in order to gain useful retention. This greater bulk has an implication for plaque accumulation and maintenance of periodontal health.

It was reported that acetal resin has a sufficiently high resilience and modulus of elasticity to allow its use in the manufacture of retentive clasps, connectors, and support elements for RPDs. Retention clasps can be excellent with retainer that lock the remaining dentition, however they may subject abutment teeth to excessive stresses \& premature tooth loss. Some clinicians aimed to reduce the weight of the prosthesis to minimize the damage to the abutment teeth, splinting some or all the abutment teeth to dissipate the forces $(8,9)$.

Arda and Arikan (10), simulated a 36-month clinical use of RPD clasps made of acetal resin and assessed their retentive force and deformation by comparison with similar clasps cast of Co-Cr. The result showed no deformation for the acetal resin clasp after 36 months of simulated clinical use unlike the Co-Cr clasp which presented an increase in the distance between the tips. However, they found that the 
acetal resin clasps require less force for insertion and removal than Co-Cr clasps even after the simulated period.

In dentistry, computer aided design (CAD)/ computer aided manufacturing (CAM) technologies have been applied in the field of prosthodontics since the 1980s. $\mathrm{CAD} / \mathrm{CAM}$ and rapid prototyping (RP) have been extensively used in maxillofacial technology and surgery $(11,12)$.

A CAD/CAM system utilizes a process chain consisting of scanning, designing and milling phases. The scanning device converts the shape of the stone model into three dimensional (3-D) units of information (voxels). The computer translates this information into a 3-D map (point cloud). The operator designs a restoration shape using the computer which generates a tool path, which is used by the milling device to create the shape from a restorative material (13).

For the assessment of chewing function, a wide variety of subjective and objective methods have been described in the dental literature $(14,15)$. Amongst the assessment of self-perceived subjective chewing function, questionnaires including oral health-related quality of life (OHRQoL) have been developed to assess the self-perceived chewing function and patient's satisfaction with chewing. Apart from these subjective measurements, objective methods and indicators have been used to assess masticatory performance (14). In most studies on masticatory performance, the degree of breakdown of a test food has been determined by sieving the comminuted food $(14,16)$.

The aim of the present in vivo study is to evaluate and compare clinically the use of Polyoxymethylene partial denture frameworks designed and fabricated by CAD/CAM technology versus the conventional cobalt chromium partial denture frameworks through both the masticatory efficiency and patient satisfaction.

\section{MATERIALS AND METHODS}

This study was conducted on twenty mandibular partially edentulous patients who were selected from the clinic of prosthodontic department, Faculty of Dentistry, Alexandria University. They had bilateral distal extension partial edentulous area (Kennedy class I) with at least bilateral first premolar, with almost of all the opposing maxillary natural teeth., had Angle's class I ridge relationship and sufficient inter-maxillary space with average ridge form and height with healthy oral tissue. All patients were selected with no previous removable prosthetic management and free from any systemic disorders. Patients with bad oral hygiene or smoking habits were excluded from this study. Written informed consents were obtained from all patients sharing in the study.

Two types of partial dentures were constructed for each patient

- Type I: Polyoxymethylene partial denture designed and fabricated by Using CAD/CAM Technology.

- Type II: Cobalt chromium partial denture fabricated using conventional technique.

At time of denture insertion, the masticatory efficiency was evaluated for each patient during wearing the both types of dentures (each separately).

Following this evaluation stage, the patients were divided randomly into two equal groups (10 patients for each group).
By using the cross over method, the groups were as follow:

Group A (10 patients): used their type I partial dentures for three months then were replaced by type II partial dentures for the following three months.

Group B (10 patients): used their type II partial dentures for three months then were replaced by type I partial dentures for the following three months.

- After each follow up period, each patient was clinically evaluated through the followings: Masticatory efficiency and Patient satisfaction.

\section{Procedures of dentures construction}

Preliminary impression was made using alginate impression material (Hydrogum 5, Zhermack SPA, Italy) then poured to get the study cast. The study cast was scanned using a digital scanner (SHERA echo-scan 7, Germany) to get virtual digital model (Fig. 1). Using the specially preformed CAD software (Shera I digital software), the digital model was surveyed (Fig. 2) and the suitable design was detected having bilateral RPI clasp, lingual plate major connector, mesial occlusal rests at both abutments and two cingulum rests at bilateral canines. The needed mouth preparations were detected then performed in the patient mouth for all patients. Final impressions were done twice for every patient using custom made trays with border molding with green compound (Kerr Compound Green Stick, Orange, CA, USA) and medium body rubber base impression material (Thixoflex M, Zhermack SPA, Italy). The impressions were poured to get two master casts for each patient.

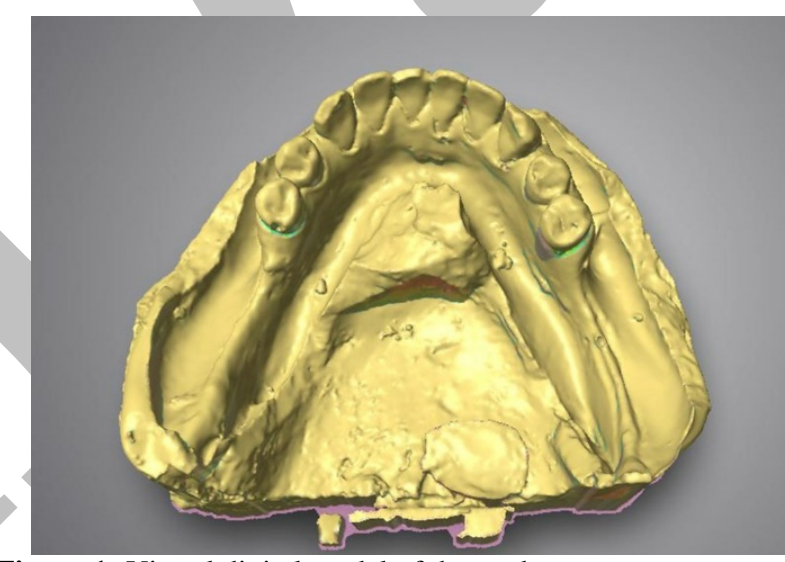

Figure 1: Virtual digital model of the study cast.

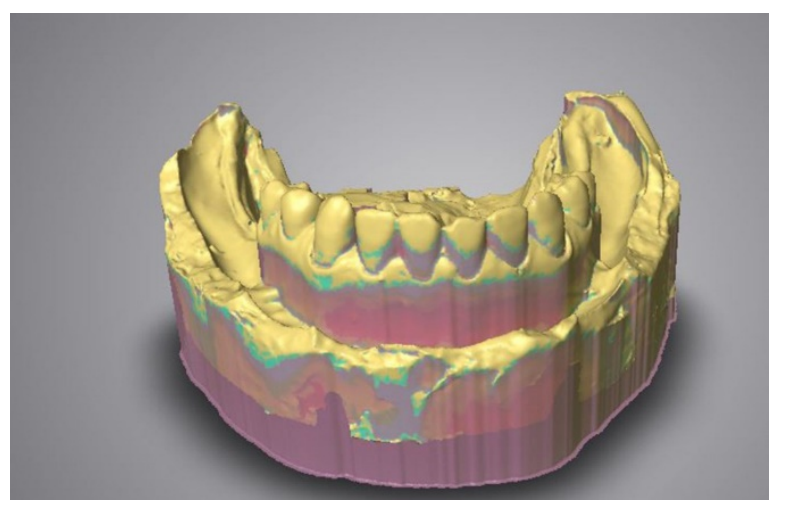

Figure 2: The digital model was surveyed.

Framework fabrication

For type I dentures

Utilizing the CAD software, the first master cast for each patient was scanned again to produce a master digital model. Using CAD software allows surveying the model for 
detection of desirable and undesirable undercuts. All undesirable undercuts were blocked using automatic block out function. Once the block-out was completed, the next step was to design the framework. Once the RPD framework design was completed (Fig. 3) it was sent to the milling machine (SHERA eco mill 5x, Germany) in the form of STL (stereo lithography) to get the Polyoxymethylene framework (Fig. 4).

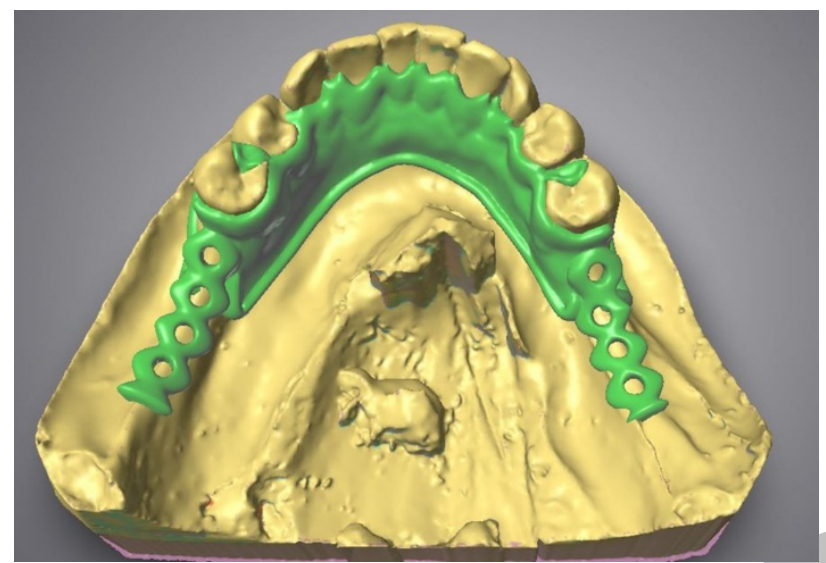

Figure 3: The digital master model with the virtual framework.

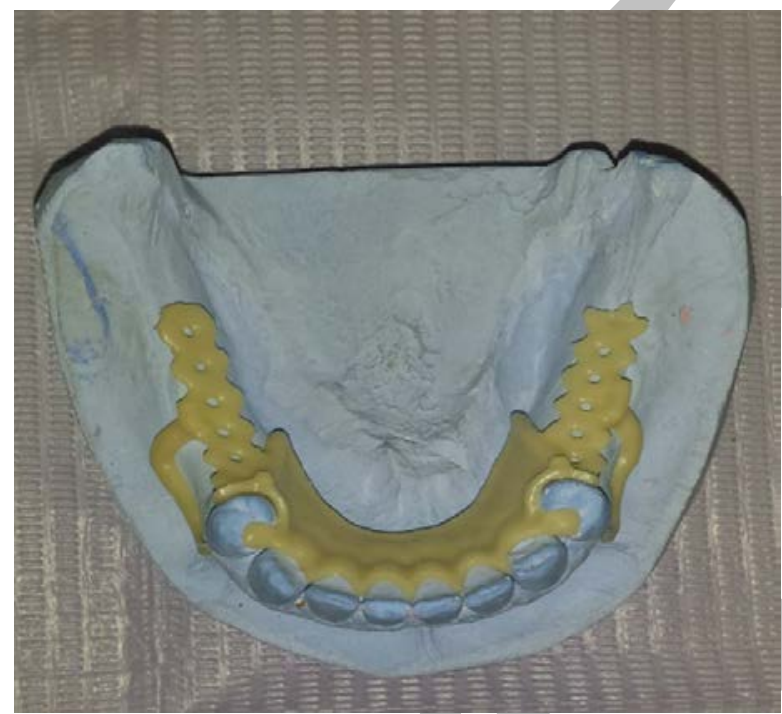

Figure 4: The finished Polyoxymethylene framework on the master cast.

\section{For type II dentures}

Master cast preparations and duplication were done to get the refractory cast. Wax pattern with the same design of type I denture was made on the refractory cast. Casting was completed by the conventional manner to get the cobalt chromium framework.

\section{Continuing the prosthetic procedures for both framework types}

Each framework was tried intra-orally for retention and stability. The relation of the maxilla to T.M.J was transferred to the Whip Mix adjustable articulator by the help of whip mix face bow transfer. Trial dentures with record blocks were fabricated on the framework and registration of maxillomandibular relation was carried out. The mandibular cast was mounted using a centric inter occlusal record. The fabrication of the occlusal units was done by arranging posterior acrylic teeth (Acrostone Plus teeth, Acrostone,Egypt) with the same size and cusp angle for each denture with simultaneous working side contacts with the opposing natural teeth to distribute the stress over the greatest possible area. Try in of the frameworks with the acrylic teeth intraorally was done to check proper function, esthetics and phonetics. The acrylic denture base was flasked, packed and processed with heat cure acrylic resin. Both types of RPD for each patient were inserted and verified intraorally with occlusal adjustment (Fig. 5, 6). Oral hygiene and careful post insertion instructions were advised for each patient

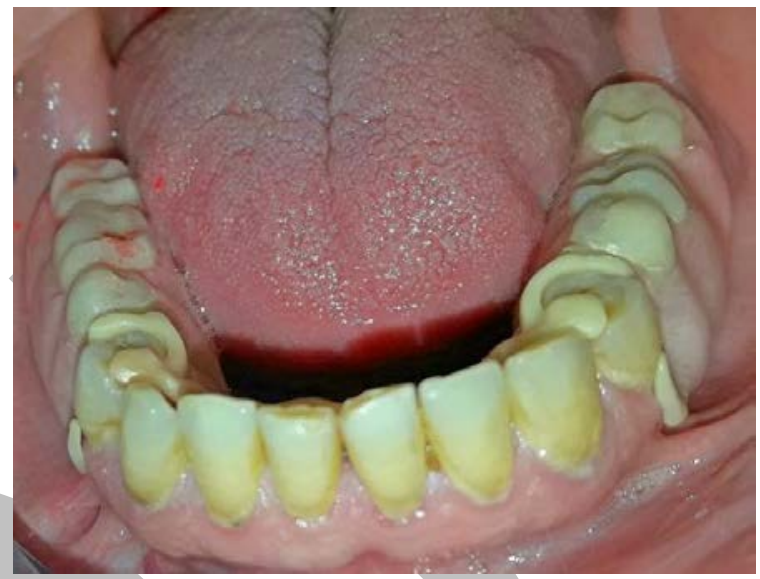

Figure 5: The finished Polyoxymethylene RPD.

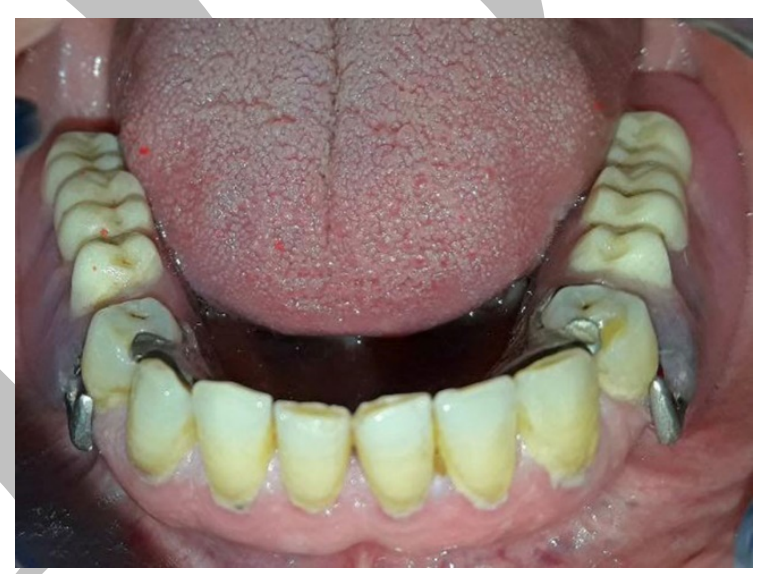

Figure 6: The finished Cobalt Chromium RPD.

\section{Evaluation methods}

The finished dentures were evaluated through: Masticatory efficiency and Patient satisfaction.

\section{A- Masticatory efficiency (15)}

Evaluation of masticatory efficiency was applied for every patient three times (at the day of insertion for both dentures separately, after three months of using one type of dentures and another following three months after using the other type of dentures).

Evaluation of masticatory efficiency was performed through a colorimetric method using a spectrophotometer. Masticatory efficiency was evaluated by measuring the chewing strength of each patient using capsulated test beads which were the artificial test-food that were prepared and manufactured at the Central lab of the Faculty of Pharmacy, Alexandria University.

The patients were seated on a chair with back rest and with both feet resting on the ground. Then they were instructed to chew the beads in their habitual manner. After mastication the test was stopped after $20 \mathrm{~s}$ and the beads were collected into a container identified by subject and test number. When the capsule was chewed, the granules inside each capsule were 
broken and the dye was spread within the capsule according to the chewing strength. Masticatory efficiency was calculated by measuring the dye concentration in a solution where water was added to the capsule components.

The content of the capsule was dissolved in $5 \mathrm{~mL}$ of distilled water by mixing constantly for $30 \mathrm{~s}$. The solution was then filtered through a qualitative filter paper and the extracted dye was quantified in nanometers (nm) with a (UV-Visible- Helios $\alpha$ Spectrophotometer). It allows the measurement of masticatory efficiency on the basis of the concentration of extracted dye, which is expressed in absorbance at 310 and $525 \mathrm{~nm}$. Increase of the concentration of the extracted dye indicated improvement of the masticatory efficiency (high chewing strength), while reduced concentration indicated reduced masticatory efficiency (low chewing strength).

\section{B- Patient satisfaction (17)}

In the present study all patients general satisfaction was evaluated after each follow up period by a score system in regard to esthetics, retention, stability, comfort, speech, tasting, pain, chewing efficiency and each test was evaluated according to patients questionnaire .They described their satisfaction as: well satisfied, satisfied or not satisfied and each answer was recorded and scored with a number 2, 1, 0 respectively and the general patient satisfaction was evaluated after the statistical calculation and analysis.

\section{Statistical analysis of the data}

Data were fed to the computer and analyzed using IBM SPSS software package version 20.0. (Armonk, NY: IBM Corp).The Kolmogorov- Smirnov, Shapiro and D’agstino tests were used to verify the normality of distribution of variables, Student ttest was used to compare two groups for normally distributed quantitative variables while, Paired t-test was assessed for comparison between different periods. Significance of the obtained results was judged at the $5 \%$ level.

\section{RESULTS}

\section{1- Evaluation of the masticatory efficiency}

Table (1) showed comparison of mean concentration of the dye in $(\mathrm{ug} / \mathrm{mL})$ for all patients at day of insertion with use of both types of partial dentures (separately). There was slight increase in the mean of dye concentration (indicating increased masticatory efficiency) by using type I RPD when compared with using type II RPD but without statistical significant value $(\mathrm{P}=0.133)$.

Table (1): Comparison of mean concentration of the dye in (ug/ml) for all patients at day of insertion for both types of partial dentures.

\begin{tabular}{|c|c|c|}
\hline & $\begin{array}{c}\text { At day of insertion of } \\
\text { type I partial denture } \\
(\mathbf{n}=\mathbf{2 0})\end{array}$ & $\begin{array}{c}\text { At day of insertion of } \\
\text { type II partial denture } \\
(\mathbf{n}=\mathbf{2 0})\end{array}$ \\
\hline $\begin{array}{c}\text { Mean } \pm \\
\text { SD. }\end{array}$ & $11.35 \pm 1.45$ & $10.90 \pm 10.90$ \\
\hline $\mathbf{t}(\mathbf{p})$ & \multicolumn{2}{|c|}{$1.569(0.133)$} \\
\hline
\end{tabular}

$\mathrm{t}, \mathrm{p}$ : $\mathrm{t}$ and $\mathrm{p}$ values for Paired t-test for comparing between the two types

Table (2) showed comparison of mean concentration of the dye in (ug/mL) for all patients of both groups at different follow up periods.
Table (2): Comparison of mean concentration of the dye in (ug/ ml) for all patients of both groups at different follow up periods.

\begin{tabular}{|c|c|c|c|}
\hline \multicolumn{4}{|c|}{ Group (A) } \\
\hline \multicolumn{2}{|c|}{ Using Type I partial denture } & \multicolumn{2}{|c|}{ Using Type II partial denture } \\
\hline $\begin{array}{c}\text { At day of } \\
\text { insertion } \\
(n=10)\end{array}$ & $\begin{array}{l}\text { After } 1^{\text {st }} \\
\text { follow up } \\
\text { period } \\
(n=10)\end{array}$ & $\begin{array}{c}\text { At day of } \\
\text { insertion } \\
(\mathbf{n}=10)\end{array}$ & $\begin{array}{c}\text { After } 2^{\text {nd }} \\
\text { follow up } \\
\text { period } \\
(\mathbf{n}=10)\end{array}$ \\
\hline $11.42 \pm 1.78$ & $13.90 \pm 3.62$ & $10.59 \pm 1.52$ & $12.62 \pm 1.69$ \\
\hline \multicolumn{4}{|c|}{$\mathbf{t}_{1}\left(\mathbf{p}_{1}\right)=2.839^{*}\left(0.019^{*}\right), \mathbf{t}_{\mathbf{2}}\left(\mathbf{p}_{2}\right)=3.148^{*}\left(0.012^{*}\right), \mathbf{t}_{3}\left(\mathbf{p}_{3}\right)=0.846(0.420)$} \\
\hline \multicolumn{4}{|c|}{ Group (B) } \\
\hline \multicolumn{2}{|c|}{ Using Type II partial denture } & \multicolumn{2}{|c|}{ Using Type I partial denture } \\
\hline $\begin{array}{l}\text { At day of } \\
\text { insertion } \\
(\mathbf{n}=10)\end{array}$ & $\begin{array}{l}\text { After } 1^{\text {st }} \\
\text { follow up } \\
\text { period } \\
(\mathbf{n}=10)\end{array}$ & $\begin{array}{l}\text { At day of } \\
\text { insertion } \\
(\mathbf{n}=10)\end{array}$ & $\begin{array}{c}\text { After } 2^{\text {nd }} \\
\text { follow up } \\
\text { period } \\
(\mathrm{n}=10)\end{array}$ \\
\hline $11.21 \pm 1.12$ & $12.38 \pm 1.12$ & $11.29 \pm 1.10$ & $13.74 \pm 3.71$ \\
\hline \multicolumn{4}{|c|}{$\mathbf{t}_{4}\left(\mathbf{p}_{4}\right)=2.872^{*}\left(0.018^{*}\right), \mathbf{t}_{5}\left(\mathbf{p}_{5}\right)=1.742(0.116), \mathbf{t}_{6}\left(\mathbf{p}_{6}\right)=0.967(0.359)$} \\
\hline & $\begin{array}{c}t_{7}\left(\mathbf{p}_{7}\right)=1.276(0 \\
218)\end{array}$ & & $\begin{array}{c}\mathbf{t}_{8}\left(\mathbf{p}_{8}\right)=0.869(0 . \\
396)\end{array}$ \\
\hline
\end{tabular}

$t_{1}, p_{1}$ : $t$ and $p$ values for Paired t-test for comparing between At day of insertion of and After 1st follow up period using Type I partial denture in group (A)

$t_{2}, p_{2}$ : $t$ and $p$ values for Paired t-test for comparing between At day of insertion of and After $2^{\text {nd }}$ follow up period using Type II partial denture in group $(\mathrm{A})$

$t_{3}$, $p_{3}$ : $t$ and $p$ values for Paired t-test for comparing between After $\mathbf{1}^{\text {st }}$ follow up period and After 2 nd follow up period in group (A) $\mathrm{t}_{4}$, $\mathrm{p}_{4}$ : $\mathrm{t}$ and $\mathrm{p}$ values for Paired t-test for comparing between At day of insertion of and After 1st follow up period using Type II partial denture in group (B)

t5, ps: $t$ and $p$ values for Paired t-test for comparing between At day of insertion of and After $2^{\text {nd }}$ follow up period using Type II partial denture in group (B)

t6, p6: $t$ and $p$ values for Paired t-test for comparing between After $\mathbf{1}^{\text {st }}$ follow up period and After 2 nd follow up period in group (B) t7, p7: $t$ and $p$ values for Student t-test for comparing between the two groups

$t_{8}$, p8: $t$ and $p$ values for Student t-test for comparing between the two groups

*: Statistically significant at $\mathrm{p} \leq 0.05$

In group (A) with using type I partial denture there was increase in the mean of dye concentration (indicating increased masticatory efficiency) after first follow up period when compared with that at time of denture insertion with statistical significant value ( $\mathrm{p} 1=0.019$ ). After the second follow up period with using type II partial there was increase in the mean of dye concentration (indicating increased masticatory efficiency) when compared with that at time of denture insertion with statistical significant value ( $\mathrm{p} 2=0.012$ ). There was increase in the dye concentration (indicating increased masticatory efficiency) after first follow up period using type I partial denture when compared with the use of type II partial denture at the second follow up period but without statistical significant value $(\mathrm{P} 3=0.420)$.

In group (B) with using type II partial denture there was increase in the mean of dye concentration (indicating increased masticatory efficiency) after first follow up period when compared with that at time of denture insertion with statistical significant value ( $\mathrm{p} 4=0.018$ ). After the second follow up period with using type I partial there was increase in the mean of dye concentration (indicating increased masticatory efficiency); when compared with that at time of denture insertion but without statistical significant value $(\mathrm{p} 5=0.116)$. There was increase in the dye concentration (indicating increased 
masticatory efficiency) after second follow up period using type I partial denture when compared with the use of type II partial denture at the first follow up period but without statistical significant value (P6=0. 359).

There was an increase in the dye concentration (indicating increased masticatory efficiency) in group (A) after first follow up period using type I partial denture more than in group (B) after first follow up period using type II partial denture but without statistical significant value (P7=0.218). There was increase in the dye concentration (indicating increased masticatory efficiency) in group (B) after second follow up period using type I partial denture more than in group (A) after second follow up period using type II partial denture but without statistical significant value ( $\mathrm{P} 8=0.396)$.

\section{Patient satisfaction evaluation}

Table (3) showed comparison of mean of patient's satisfaction scores after the follow up periods for both groups.

Table (3): Comparison of mean of patients satisfaction scores after the follow up periods for both groups.

\begin{tabular}{|c|c|c|c|}
\hline \multicolumn{2}{|c|}{ Group (A) } & \multicolumn{2}{|c|}{ Group (B) } \\
\hline $\begin{array}{l}\text { After } 1^{\text {st }} \\
\text { follow up } \\
\text { period using } \\
\text { type I partial } \\
\text { denture } \\
(n=10)\end{array}$ & $\begin{array}{c}\text { After } 2^{\text {nd }} \\
\text { follow up } \\
\text { period using } \\
\text { type II } \\
\text { partial } \\
\text { denture } \\
(\mathrm{n}=10)\end{array}$ & $\begin{array}{l}\text { After } 1^{\text {st }} \\
\text { follow up } \\
\text { period using } \\
\text { type II } \\
\text { partial } \\
\text { denture } \\
(n=10)\end{array}$ & $\begin{array}{l}\text { After } 2^{\text {nd }} \\
\text { follow up } \\
\text { period using } \\
\text { type I partial } \\
\text { denture } \\
(n=10)\end{array}$ \\
\hline $12.30 \pm 1.34$ & $8.0 \pm 2.05$ & $7.90 \pm 1.85$ & $10.70 \pm 1.64$ \\
\hline \multicolumn{2}{|c|}{$\mathbf{t}_{\mathbf{1}}\left(\mathbf{p}_{1}\right)=6.143^{*}\left(<0.001^{*}\right)$} & \multicolumn{2}{|c|}{$\mathbf{t}_{\mathbf{2}}\left(\mathbf{p}_{2}\right)=5.056^{*}\left(0.001^{*}\right)$} \\
\hline \multicolumn{4}{|c|}{$\mathbf{t}_{3}\left(\mathbf{p}_{3}\right)=6.089^{*}\left(<0.001^{*}\right), \mathbf{t}_{4}\left(\mathbf{p}_{4}\right)=3.250^{*}\left(0.004^{*}\right)$} \\
\hline
\end{tabular}

$t_{1}\left(p_{1}\right)$ : $p$ value for Paired t-test for comparing After $1^{\text {st }}$ follow up period using type I partial denture and After $2^{\text {nd }}$ follow up period using type II partial denture in group A $t_{2}\left(p_{2}\right)$ : $p$ value for Paired t-test for comparing After $1^{\text {st }}$ follow up period using type I partial denture and After $2^{\text {nd }}$ follow up period using type II partial denture in group $B$ $t_{3}, p_{3}$ : $t$ and $p$ values for Student t-test for comparing between the two groups after first follow up period $\mathrm{t}_{4}, \mathrm{p}_{4}$ : $\mathrm{t}$ and $\mathrm{p}$ values for Student t-test for comparing between the two groups after $2^{\text {nd }}$ follow up period

*: Statistically significant at $\mathrm{p} \leq 0.05$

In group (A) there was more patient satisfaction after first follow up period with type I partial denture than after second follow up period with type II partial denture with statistical significant value $(\mathrm{P} 1<0.001)$. In group (B), there was more patient satisfaction after second follow up period with type I partial denture than after first follow up period with type II partial denture with statistical significant value $(\mathrm{P} 2<0.001)$. There was more patient satisfaction after first follow up period in group (A) with type I partial denture than after first follow up period in group (B) with type II partial denture with statistical significant value $(\mathrm{P} 3<0.001)$. There was more patient satisfaction after second follow up period in group (B)with type I partial denture than after second follow up period in group (A) with type II partial denture with statistical significant value $(\mathrm{P} 4=0.004)$
The hypothesis of this study was that the use of concentrated growth factors combined with a bone graft material could yield better results in terms of quantity and quality of osseous regeneration compared to the use of bone graft alone.

Limited studies are reported in the literature concerning the MPM. However, the effect of growth factors on bone healing and osseointegration has been extensively investigated. Lee et al. (27), in an animal study reported that the use of platelet enriched fibrin glue, a similar preparation to MPM, results in a statistically significant amount of bone gain. This result agreed with our study, where a new concept of fabricating growth factors-enriched bone graft matrix has been introduced, this offers the MPM the positional stability by stabilizing the bone particles, preserving its shape with subsequent "in situ" immobilization of the component of ridge preservation materials and this was the logical evolution of the fibrin glues function to incorporate platelets within the products (28).

The current study revealed the osteo-conductive potentials of both materials. In this study the newly formed bone was assessed histologically and histomorphometrically, and from the statistical analysis of the histomorphometric results, MPM showed better quality of bone formation regarding the homogenisity and the increased amount of the newly formed bone.

However, an interesting finding was that although the study group showed to be more significant in bone density, but the change in the mean percentage of bone was not statistically significant comparing the two groups demonstrated by $p$ value $(p=0.008)$. This means that the mean bone density is significantly higher in the study group but the pattern of improvement is nearly the same throughout time comparing the two groups. This could be attributed to the fact that the fibrin matrix in which the bone graft is suspended does not have any osteoconductive properties by its own, but the mineral fraction is the one that gives such property.

These findings agreed with Dr. Perissé (29) in its histological studies revealed the presence of monocytes inside the MPM biopsies, these monocytes are very important in bone formation as they allow a regulation of production of BMPs which are highly important proteins in the induction of bone production

Also, MPM is rich with growth factors EL Moheb (21) claimed that the MPM is the only natural and autogenous product that can offer stability to bone graft particles. He conducted a study and compared MPM to PRF and favored MPM biologically and histologically, which again was proved by our results but compared with bone graft instead revealing higher regenerative features of MPM.

Our study supported Choukroun et al. (11) results who reported a $30 \%$ decrease in the healing time needed for sinus floor augmentation prior to dental implant placement when the graft material is used in combination with plasma concentrates. The authors attributed this accelerated healing to the fibrin network and platelets growth factors. This could explain the stability of the graft volume after loading in the study group compared to the control group.

Also during manipulation, the retention in the fibrous mesh of the bone fragments or the grafting material conserves its cohesion and avoids its departure away from the recipient bed.

\section{DISCUSSION}


The use of MPM in periodontology and implant therapy has a great impact in the outcome of the grafting surgery because it enhances transport of thematerial by securing its implementation as explained before by Mazzoni and Perisse (22).

Therefore from this study we found that the use of bone filler combined with fibrin, platelets and leukocytes in the form of MPM shows a better histological evidence of hard bone formation as evidenced by its high osteoblastic activity and maturation, also proved by the histomophometrical results regarding the higher $\mathrm{p}$ value in the MPM group.

\section{CONCLUSION}

From this study, the following conclusions were obtained:

1- Polyoxymethylene RPDS designed and fabricated by Using CAD/CAM Technology showed non-significant increase in the masticatory efficiency at time of denture insertion when compared to conventional cobalt chromium partial denture.

2- Both types of RPDS showed significant increase in masticatory efficiency after the first follow up periods when compared with that at time of denture insertion.

3- Polyoxymethylene RPDS showed increase in masticatory efficiency among both group A and group B (when used after the first or the second follow up periods) when compared with at time of denture insertion.

4- Polyoxymethylene RPDS showed significant increase in masticatory efficiency when used after the first follow up period but without significant value when used after the second follow up period when compared with at time of denture insertion.

5- Polyoxymethylene RPDS showed increase in masticatory efficiency when compared with cobalt chromium RPDS but without significant value (when used after the first or the second follow up periods).

6- The present results reported significant patient satisfaction with Polyoxymethylene RPDS designed and fabricated by using CAD/CAM Technology when compared to conventional cobalt chromium partial denture.

7- Polyoxymethylene RPDS can be considered as an innovative and favorable treatment alternative to conventional cobalt chromium RPDS for partially edentulous patients.

\section{CONFLICT OF INTEREST}

The authors declare that they have no conflicts of interest.

\section{REFERENCES}

1. Moreno de Delgado M, Garcia LT, Rudd KD. Camouflaging partial denture clasps. J Prosthet Dent. 1986;55:656-60.

2. Ozcan M. The use of chair side silica coating for different dental applications: a clinical report. J Prosthet Dent. 2002;87:469-72.

3. Highton R, Caputo A, Matyas J. Force transmission and retentive capabilities utilizing labial and palatal I-bar partial dentures. J Oral Rehabil. 1987;14:489-99.

4. Pardo-Mindan S, Ruiz-Villandiego JC. A flexible lingual clasp as an aesthetic alternative: A clinical report. J Prosthet Dent. 1993;69:245-6.

5. Chow TW, Clark RK, Clarke DA, Ho GF. A rotational path of insertion for Kennedy- Class IV removable partial dentures. Br Dent J. 1988;164:180-3.

6. Prieskel HW. Precision Attachments in Dentistry. In: Preiskel HW, (ed). Precision Attachments in Dentistry. $3^{\text {rd }}$ ed. London: Henry Kimpton Ltd; 1979.

7. Aleksandruk G, Frączak B, Szymaniak L, Tutak M, Kubrak J. Adhesion of Candida albicansto solid acrylic surfaces and soft denture-lining. Protet Stomatol. 2003;53:44-9.

8. Turner JW, Radford DR, Sherriff M. Flexural properties and surface finishing of acetal resin denture clasps. J Prosthet. 1999;8:188-95.

9. Fitton JS, Davies EH, Howlett JA, Pearson GJ. The physical properties of a polyacetal denture resin. Clin Mater. 1994;17:125-9.

10. Arda T, Arikan A. An in vitro comparison of retentive force and deformation of acetal resin and cobalt chromium clasps. J Prosthet Dent. 2005;94:267-74.

11. Williams RJ, Bibb R, Eggbeer D, Collis J. Use of CAD/CAM technology to fabricate a removable partial denture framework. J Prosthet Dent. 2006;96:96-9.

12. Kanazawa M, Inokoshi M, Minakuchi S, Ohbayashi N. Trial of a CAD/CAM system for fabricating complete dentures. Dent Mater J. 2011;30:93-6.

13. Freedman M, Quinn F, O'Sullivan M. Single unit CAD/CAM restorations: a literature review. J Ir Dent Assoc. 2007;53:38-45.

14. Van der Bilt A. Assessment of mastication with implications for oral rehabilitation. Review. J Oral Rehabil. 2011;38:754-80.

15. Sato H, Fueki K, Sueda S, Shiozaki T, Kato M, Ohyama T. A new and simple method for evaluating masticatory function using newly developed artificial test food. J Oral Rehabil. 2003;30:68-73.

16. Fontijn-Tekamp FA, Slagter AP, Van der Bilt A, Van't Hof MA, Witter DJ, Kalk W, et al. Biting and chewing in overdentures, full dentures, and natural dentitions. J Dent Res. 2000;79:1519-24.

17. Sato Y, Hamada S, Akagawa Y, Tsuga K. A method for quantifying overall satisfaction of complete denture patients. J Oral Rehabil. 2000;27:952-7.

18. Bortun CM, Sandu L, Porojan S. Using of light-curing waxes in the removable partial denture technology. Issues. 2017;2016:2015.

19. Miyazaki T, Hotta Y, Kunii J, Kuriyama S, Tamaki Y. A review of dental CAD/CAM: current status and future perspectives from 20 years of experience. Dent Mater J. 2009;28:44-56.

20. Salah El Din F, El-Shabrawy SM, El-Gebaly MF. The accuracy Partial Denture Frameworks Designed and fabricated By Using CAD/ CAM Technolgy (Invitro study). Int J Sci Res. 2016;5:328.

21. Paphangkorakit J, Chaiyapanya N, Sriladlao P, PIMSUPA S. Determination of chewing efficiency using muscle work. Arch Oral Biol. 2008;53:533-7.

22. Slagter A, Bosman F, Bilt A. Comminution of two artificial test foods by dentate and endentelous subjects. J Oral Rehabil. 1993;20:59-76.

23. Heydecke G, Akkad AS, Wolkewitz M, Vogeler M, Türp JC, Strub JR. Patient ratings of chewing ability from a randomized crossover trial: lingualized versus first premolar/canine-guided occlusion for complete dentures. Gerodontology. 2007;24:7786.

24. Esraa MA. Colorimetric comparative analysis of masticatory efficiency in complete dentures weares with two different occlusal concepts. M.Sc. Thesis. Faculty of Dentistry, Alexandria University. 2014.

25. Celebic A, Knezovic-Zlataric D. A comparison of patient's satisfaction between complete and partial removable 
denture wearers. J Dent. 2003;31:445-51.

26. Sierpińska T, Gołębiewska M. Effect of removable partial dentures on the masticatory function improvement. Protet Stomatol. 2007;57:176-82.

27. Ducia CC, Simone MB, Eduardo DLF, Elken GR, Cassiano KR, Rosemary SAS. Functional evaluation of oral rehabilitation with removable partial dentures after five years. J Appl Oral Sci. 2006;14:111-6.

28. Macura-Karbownik A, Chladek G, Żmudzki J, Kasperski J. Chewing efficiency and occlusal forces in PMMA, acetal and polyamide Acta Bioeng Biomech. 2016;18:137-44.

29. Lekha K, Savitha NP, Roseline M, Nadiger RK. Acetal resin as an esthetic clasp material. J Interdiscip Dent. 2012;2:11-4.

30. Al-Jammali ZMJ, Al Nakkash WAH. Clinical evaluations for the masticatory efficiency of heat cure resin and flexible types of denture base materials. J Bagh College Dent. 2013;25:57-61.

31. Mustafa GM, Abed AlBaki MA, Naji SA. Comparing the Effects of Denture Base Materials on Hygiene of Mucosal Denture Bearing Area. Tikrit J Dent Sci. 2013;1:71-6.

32. Taleb FAA, Eltorky IR, ElSheikh MM, Moula SA. Patient satisfaction and radiographyical evaluation of acetal resin retentive clasp arm versus conventional clasp on abutment teeth in upper unilateral removable partial dentures. J Am Sci. 2013;9:425-32.

33. Kotake M, Wakabayashi N, Ai M, Yoneyama T, Hamanaka H. Fatigue resistance of titanium-nickel alloy cast clasps. Int J Prosthodont. 1997; 10:547-52.

34. Bortun C, Lakatos S, Sandu L, Negrutiv M, Ardelean L. Metal free removable partial dentures made of thermoplastic material. TMJ 2006;56:80-7. 